\title{
Coaxial Current Transformer for Test and Characterization of High-Power Semiconductor Devices Under Hard and Soft Switching
}

\author{
Renato O. C. Lyra, Student Member, IEEE, Braz J. Cardoso Filho, Member, IEEE, Vinod John, Member, IEEE, and \\ Thomas A. Lipo, Fellow, IEEE
}

\begin{abstract}
The use of a coaxial current transformer (CCT) is an interesting choice for pulsed measurement of current through power devices during switching transients. The CCT is used to reflect current for convenient external measurement with minimal insertion impedance in the critical power circuit. This paper analyzes the characteristics of the CCT and explains how it can be integrated into test setups for both press-pack and module packages. Finite-element techniques are applied to the study of the CCT to obtain detailed electrical and magnetic characteristics. Current distribution in the primary and secondary circuits, flux densities, and insertion inductance and resistance are among the design information that can be obtained through finite-element analysis. Analytical and numerical results are obtained for the proposed CCT that is integrated in test setups for MOS turn-off thyristors (press-pack) and high-voltage insulated gate bipolar transistors (module) characterization.
\end{abstract}

Index Terms-Coaxial current transformer, current measurement, semiconductor device characterization.

\section{INTRODUCTION}

$\mathbf{T}$ HE development of power semiconductor devices that are capable of switching at high frequencies and high power levels has created a challenge for building device testing and characterization setups with high bandwidth, current, and voltage range. Insertion of a current measurement device in series with the power switch adds significant parasitic inductance to the power circuit, modifying the device current waveforms during switching transients. Addition of stray inductance is

Paper IPCSD 99-104, presented at the 1999 Industry Applications Society Annual Meeting, Phoenix, AZ, October 3-7, and approved for publication in the IEEE TRANSACTIONS ON INDUSTRY APPLICATIONS by the Industrial Power Converter Committee of the IEEE Industry Applications Society. Manuscript submitted for review June 1, 1999 and released for publication February 25, 2000.

R. O. C. Lyra and T. A. Lipo are with the Department of Electric and Computer Engineering, University of Wisconsin, Madison, WI 53706 USA (e-mail: lyra@ieee.org; lipo@engr.wisc.edu).

B. J. Cardoso Filho is with the Departamento Engenharia Eletrica, Universidade Federal de Minas Gerais, Belo Horizonte, MG 31270-901, Brazil (e-mail: cardosob@cpdee.ufmg.br).

V. John was with the Department of Electric and Computer Engineering, University of Wisconsin, Madison, WI 53706 USA. He is now with the Electrical Systems and Technologies Laboratory, Corporate Research and Development, General Electric Company, Schenectady, NY 12309 USA (e-mail: john@crd.ge.com).

Publisher Item Identifier S 0093-9994(00)04771-X. particularly critical in topologies employing resonant snubber structures.

The alternatives available for current measurement are coaxial current shunts, Rogowski coils, current transformers, and Hall-sensors-based current probes [1], [2]. However, for the test and characterization of power switches, coaxial current shunts and Rogowski coils are commonly used [3]. The coaxial current transformer (CCT) [1], [4] is an interesting choice for measurement of the current through power devices since the coaxial structure of the primary circuit leads to extremely low insertion inductance. This paper analyzes the characteristics of the current measurement device and explains how it can be integrated into a test setup for both press-mounted and module packages to achieve high power and high bandwidth measurements. Finite-element techniques are applied to the study of the CCT to obtain design information on current distribution in the primary and secondary circuits, flux densities, insertion inductance and resistance, and gain at different operating frequencies.

Two different test setups were built-one for press-pack devices, such as MOS turn-off (MTO) thyristors [5] and the other for power modules, such as insulated gate bipolar transistors (IGBT's) [6]. Both setups use similar CCT structure. Analytical, numerical, and experimental results are presented in this paper.

\section{TEST SETUP DESCRIPTION}

The test power circuit consists of a commutation cell, which reproduces the transient experienced by the switching device. A cascade connection of two current transformers is used for current measurement as shown in Fig. 1. The CCT is inserted directly in the power circuit. The transformer employs a wound-tape toroidal core. The secondary winding corresponds to ten turns of copper tape wound around the toroidal core. The primary side of the transformer was built by machining a toroidal shape from a solid copper bar, with the proper dimensions to accommodate the transformer core and secondary winding.

\section{A. Press-Pack Devices}

The high-power (pulsed) test setup implemented for the evaluation of the resonant snubbers in current-source converter 


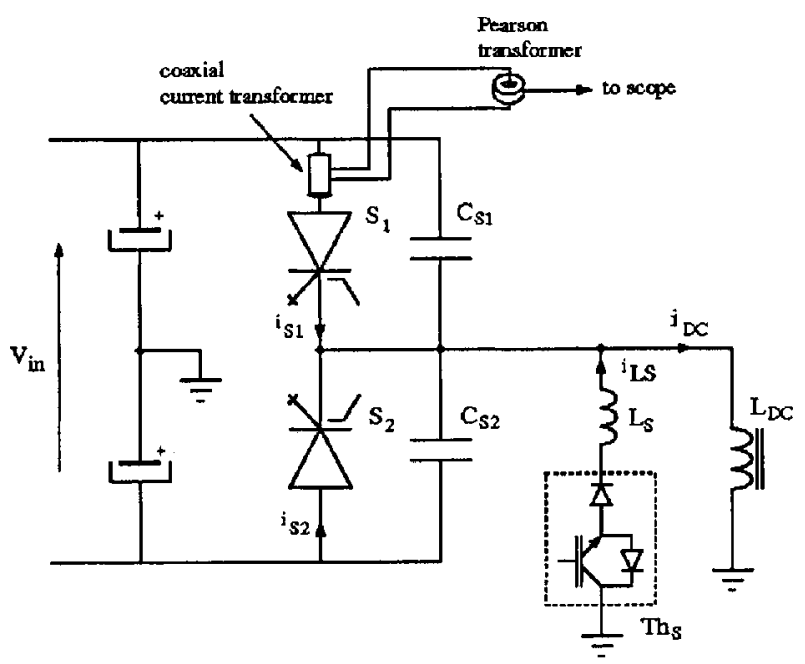

Fig. 1. High-power (pulsed) test setup circuit employing MTO's.

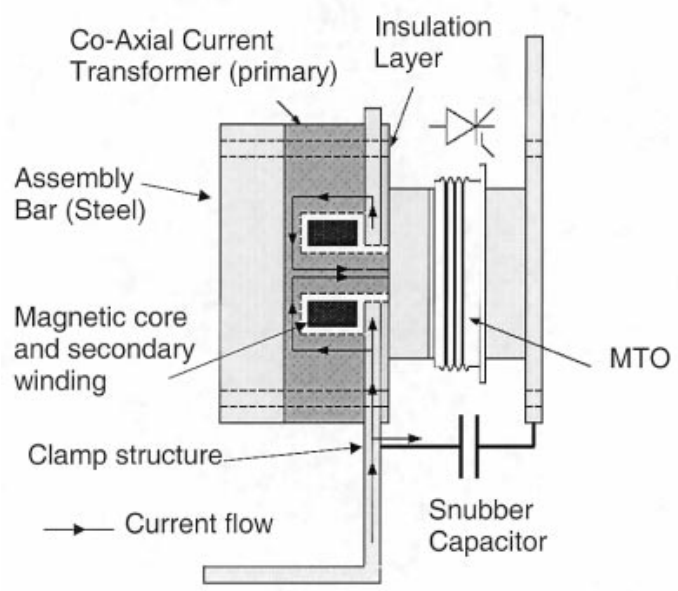

Fig. 2. Detail of assembly of the CCT for press-pack devices.

topologies is depicted in Fig. 1. MTO devices are employed in the main switches $\left(S_{1}\right.$ and $\left.S_{2}\right)$. A series-connected IGBT and fast-recovery diode are employed as the snubber switch $\left(\mathrm{Th}_{S}\right)$.

The test circuit in Fig. 1 is capable of reproducing both passive and active commutation sequences with minimum hardware and control complexity. In this circuit, the snubber driving voltage is set for optimal commutation conditions with the snubber driving voltage derived from the center tap of the input supply $V_{\text {in }}$. Near-optimal commutation conditions can be set by introducing an independent supply to set the snubber driving voltage or by splitting the input voltage in multiple levels [5].

Fig. 2 shows a detail of the power setup for press-pack devices illustrating the connection of the primary winding of the CCT to the MTO. Notice that this arrangement allows the measurement of the current through the power device only and does not include the snubber capacitor current. The current through the shorted secondary winding of the coaxial transformer is then measured using a commercial current transformer (Pearson 411). The total gain of the cascade connection is $0.01 \mathrm{~V} / \mathrm{A}$ (with the oscilloscope at $1 \mathrm{M} \Omega$ input impedance).

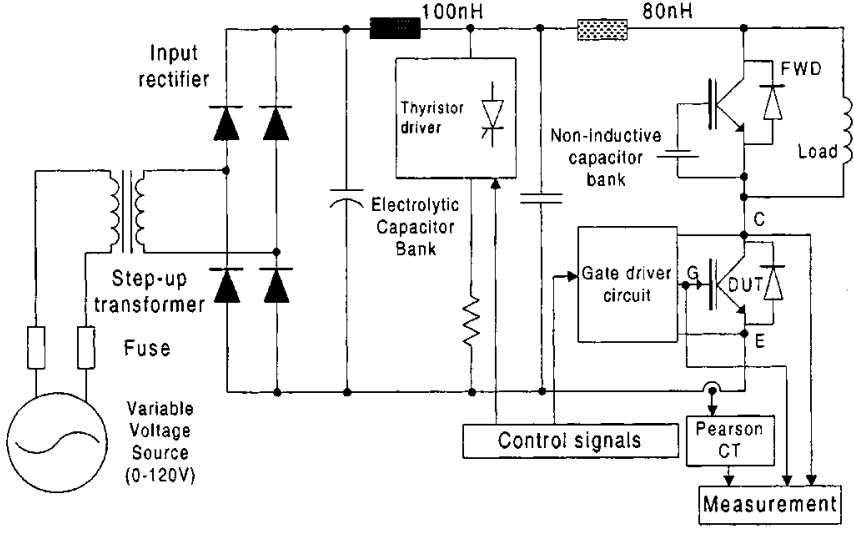

Fig. 3. The test setup for the hard-switched voltage-source converter leg using IGBT modules.

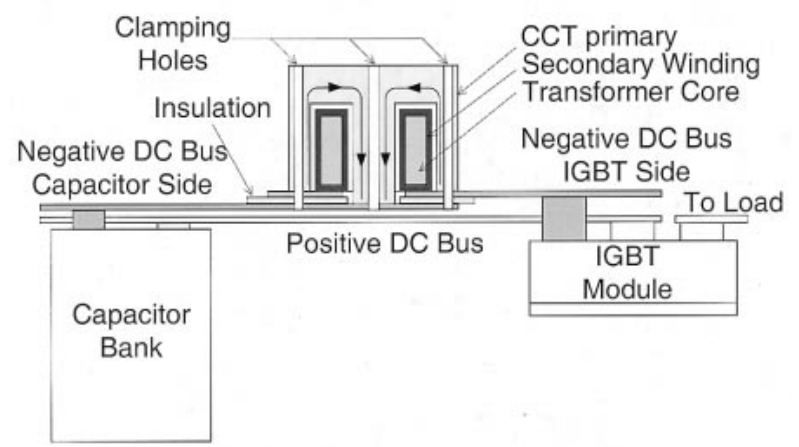

Fig. 4. Details of assembly of the CCT for module package.

\section{B. Module Package Devices}

For power modules like IGBT's, the CCT is mounted directly on the laminated bus connection to the lower IGBT emitter terminal as shown in Fig. 3. The test setup consists of one leg on a hard-switched voltage-source inverter. The test setup is a buck converter for characterization of the IGBT module. The CCT is mounted on the negative dc bus, between the high-frequency dc capacitors and the emitter of the IGBT module, as shown in Fig. 4. In the case of low power modules, it is possible to connect the center post of the CCT directly to the power connections of the module. High-current high-voltage insulated gate bipolar transistors (HVIGBT's) have multiple emitter and collector power connections. Using the CCT in the dc bus results in better symmetry in the impedance seen by the power terminals of the module. The IGBT is switched in a double-pulsed manner to study the switching characteristics.

\section{ANALYSIS OF CCT}

The CCT can be simplified as long coaxial tubes for the purpose of analytical investigation. The different radii of the crosssection of the CCT are shown in Fig. 5. The flux linkage in the CCT is calculated assuming that current flows uniformly in these tubes. The thickness of the tubes is determined by the skin depth at a given frequency.

The flux linkage of the primary winding consists of leakage in the center conductor, leakage in the gap between the primary 


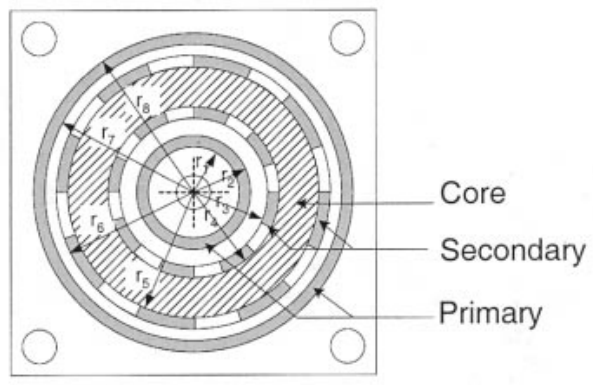

Fig. 5. Details of assembly of the CCT for module package.

and secondary, mutual flux, and leakage in the outer primary conductor. The mutual inductance is given by

$$
L_{m}=\frac{\mu_{\text {core }} h}{2 \pi} \ln \left(\frac{r_{\tilde{s}}}{r_{3}}\right)
$$

where $h$ is the height of the CCT.

The leakage inductance of the primary winding can be calculated to be

$$
\begin{aligned}
L_{\mathrm{lp}}= & \frac{\mu_{\circ} h}{2 \pi}\left\{\frac { 1 } { ( r _ { 2 } ^ { 2 } - r _ { 1 } ^ { 2 } ) ^ { 2 } } \left[r_{1}^{4} \ln \left(\frac{r_{2}}{r_{1}}\right)\right.\right. \\
& \left.+\frac{r_{2}^{4}-r_{1}^{4}}{4}-r_{1}^{2}\left(r_{2}^{2}-r_{1}^{2}\right)\right]+\ln \left(\frac{r_{3}}{r_{2}}\right) \\
& +\ln \left(\frac{r_{7}}{r_{5}}\right)+\frac{1}{\left(r_{8}^{2}-r_{7}^{2}\right)^{2}}\left[r_{8}^{4} \ln \left(\frac{r_{8}}{r_{7}}\right)\right. \\
& \left.\left.+\frac{r_{8}^{4}-r_{7}^{4}}{4}-r_{8}^{2}\left(r_{8}^{2}-r_{7}^{2}\right)\right]\right\} .
\end{aligned}
$$

The flux leakage due to the end connection in the primary winding is neglected in this analysis, but is considered in the three-dimensional (3-D) finite-element analysis (FEA) analysis. If the secondary shields the entire core area, then there is no leakage inductance associated with the secondary in a coaxial structure. Hence, the leakage inductance of the secondary is only the parasitic inductance of the external leads. This can be minimized by keeping the external loop of the secondary small and using a sandwich of copper tape for the winding. The skin depth in the windings is given by

$$
\delta=\sqrt{\frac{2}{\omega \sigma \mu_{\mathrm{copper}}}} .
$$

The resistance of the primary winding can be calculated using

$$
r_{p}=\frac{\rho h}{\pi}\left[\frac{1}{r_{2}^{2}-r_{1}^{2}}+\frac{1}{r_{8}^{2}-r_{7}^{2}}+\frac{1}{2 h \delta} \ln \left(\frac{r_{7}}{r_{2}}\right)\right] .
$$

The resistance of the secondary tape is calculated ignoring the skin effect because its thickness is designed to be smaller than the skin depth at the maximum frequency considered.

Using a simple model of a transformer with winding resistance, leakage inductance, and mutual inductance, we can calculate the primary current to secondary current transfer characteristics of the CCT to be

$$
H(s)=\frac{L_{m}}{L_{m}+L_{l s^{\prime}}}\left(\frac{s}{s+r_{s^{\prime}} /\left(L_{m}+L_{l s^{\prime}}\right)}\right) .
$$

The lower limit of the frequency response of the CCT is set by the magnetizing inductance. The value of $L_{m}$ can be increased by using a high permeability material like "supermalloy" to improve the low-frequency response. The upper frequency limit on

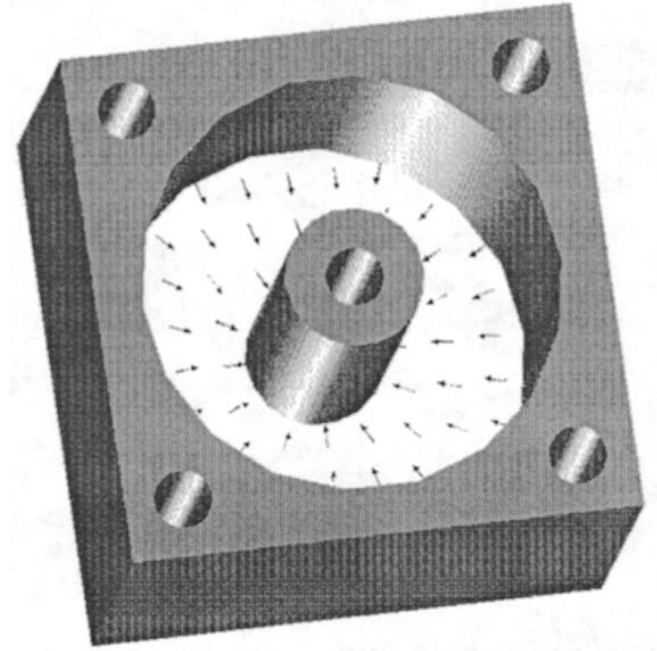

(a)

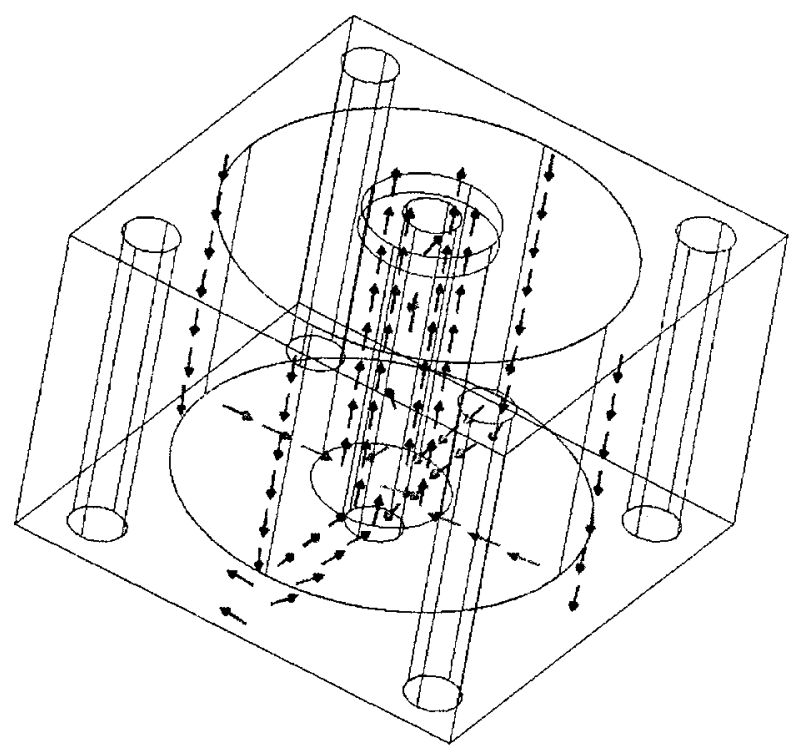

(b)

Fig. 6. Geometry of the CCT primary showing magnetostatic solution. (a) Current flow at the end section. (b) Three-dimensional primary winding showing current flow.

the measurement is determined by parasitic capacitance of the windings, and shielding effect of the core used in the setup [7].

\section{Finite-Element ANALYsis (FEA)}

FEA has been carried out to verify and define the design procedures of the CCT. An eddy-current finite-element simulation package is used to simulate the transformer behavior supplied by a high-frequency ac current.

In this paper, finite-element results are obtained mainly using a two-dimensional (2-D) model for the current transformer. The CCT primary circuit is also simulated using 3-D FEA. The results for the primary circuit impedance using both 2-D and 3-D analysis are equivalent, indicating that using 2-D analysis is sufficient in the characterization.

The current flow for 3-D magnetostatic analysis is shown in Fig. 6. As frequency increases, current flows closer to the conductors' surfaces as shown in the 2-D current distribution 


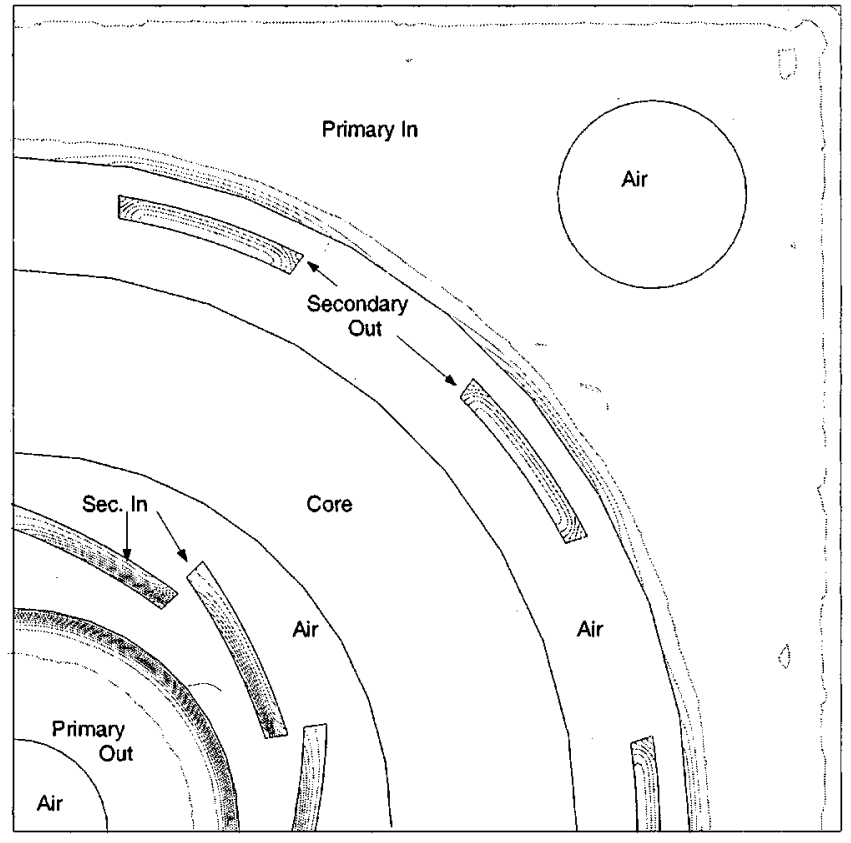

Fig. 7. Detail of current density contour plot for two-dimensional analysis at 400-A/50-kHz primary current.

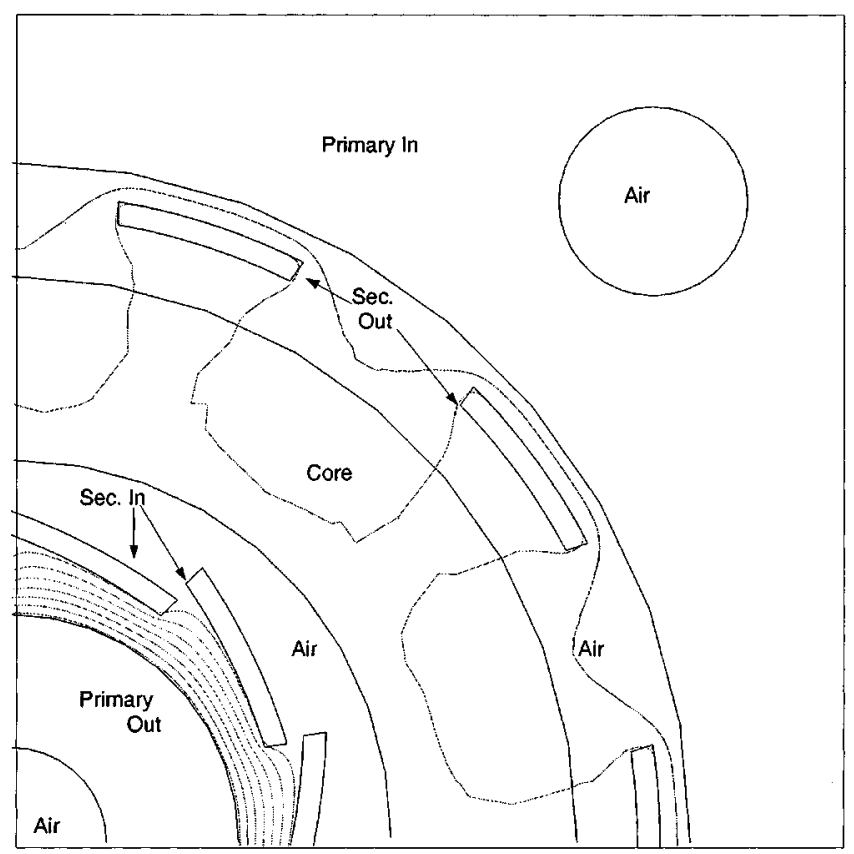

Fig. 8. Detail of flux lines plot for two-dimensional analysis at $400-\mathrm{A} / 50-\mathrm{kHz}$ primary current.

(Fig. 7). This contributes to a more flexible transformer design since it can be constructed to adapt mechanically to given test setup dimensions.

In the coaxial structure, magnetic flux inside the primary circuit determines the transformer insertion impedance. The circulation of current in the secondary winding creates an opposite flux inside the core, having a shielding effect on the space occupied by the core. Two important facts arise from this shielding effect. Firstly, the primary impedance is reduced since the effective loop area is reduced. Secondly, the flux level in the core

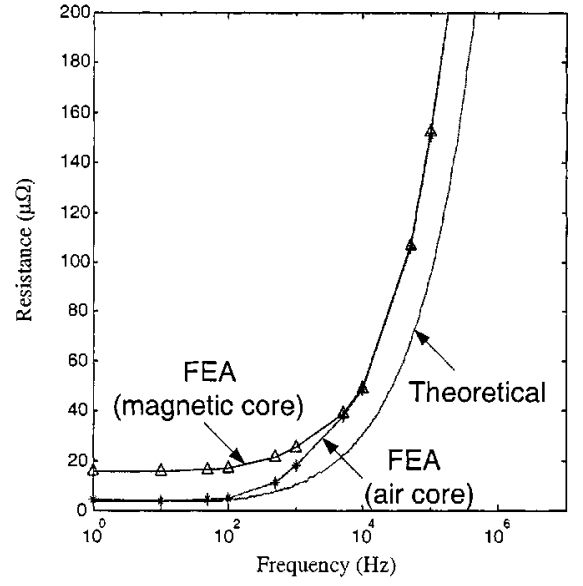

(a)

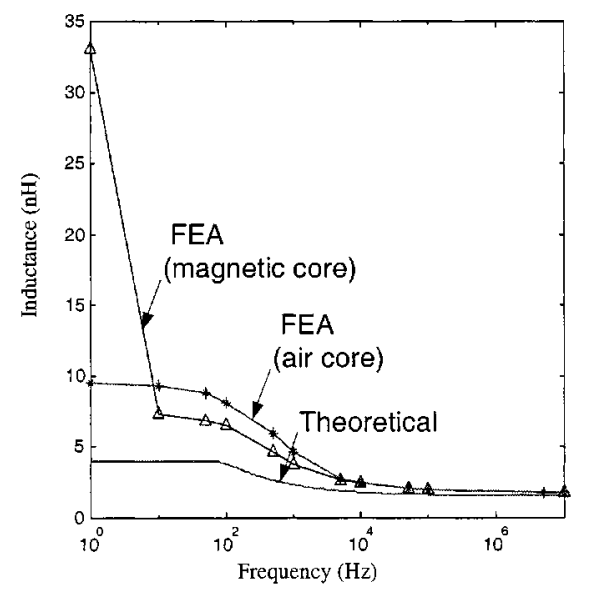

(b)

Fig. 9. CCT insertion impedance for sinusoidal excitation. Comparison of two-dimensional FEA with magnetic and air core, and theoretical results. (a) Comparison of resistance. Resistance at $10 \mathrm{MHz}$ is $1.58 \mathrm{~m} \Omega$ (FEA) and 1.0 $\mathrm{m} \Omega$ (theoretical). (b) Comparison of inductance.

is kept low, avoiding core saturation. Fig. 8 shows the flux lines in the transformer for a $50-\mathrm{kHz}$ primary current. It can be seen that the flux lines are mainly in the space between primary and secondary windings. This distribution and, therefore, the transformer parameters, vary with the input frequency.

The variation of primary resistance and inductance for a frequency range from $1 \mathrm{~Hz}$ to $10 \mathrm{MHz}$ is shown in Fig. 9(a) and (b), respectively. At low frequencies, the core shielding effect of the secondary is reduced and the primary circuit sees a high permeability flux path in the core. Also, the skin depth increases at lower frequency. This causes the primary impedance to increase. As the frequency increases, the flux path is relocated to outside the secondary winding (low permeability air) and, thus, the primary inductance decreases. Primary resistance, on the other hand, increases with frequency as the conductor effective area reduces due skin effect.

For higher frequencies, the core could be eliminated since it no longer determines the flux levels in the transformer. However, it is still important to assure the coupling between primary and secondary circuits. This fact is demonstrated using an input current peak of $400 \mathrm{~A}$ and determining the ratio between primary and secondary currents (Figs. 10 and 11). Fig. 10 


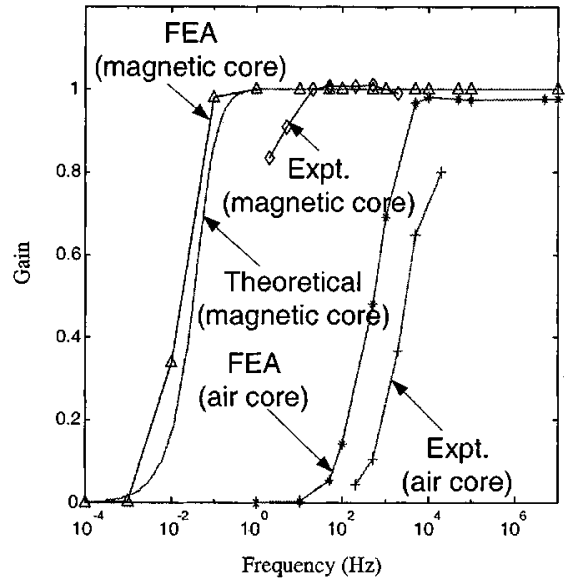

Fig. 10. CCT gain for the cases: FEA with magnetic core, air core, and theoretical analysis with magnetic core.

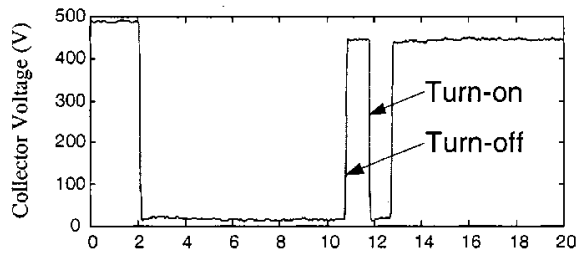

(a)

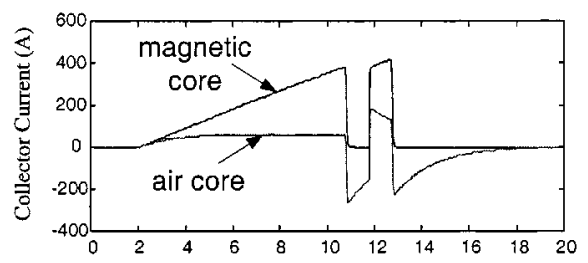

(b)

Time $(\mu s)$

Fig. 11. Double-pulse test profile. (a) The time corresponding to the turn-on and turn-off point. (b) Comparison of IGBT collector current measurement using an air core and magnetic core for the CCT.

shows that ideal primary to secondary ampere-turns ratio is obtained for frequencies over $2 \mathrm{~Hz}$ with the magnetic core. This frequency could be further reduced using higher permeability core material. Without the magnetic core, the ampere-turns ratio is close to unity only for frequencies over $20 \mathrm{kHz}$. The gain of the CCT is lower than that given by the turns ratio because the ratio between magnetizing and secondary leakage inductance is smaller in the case of the air core.

The transformer insertion impedance does not change for high frequencies due the core shielding effect. Fig. 9 also shows primary resistance and inductance for air core transformer. Only for low frequencies, the transformer parameters are changed with the use of an air core.

\section{EXPERIMENTAL RESULTS}

\section{A. CCT Characterization Using IGBT Test Setup}

1) Insertion Impedance: The IGBT test setup is used to experimentally evaluate the CCT parameters. With a fixed inductive load $(225 \mu \mathrm{H})$, a double-pulsed gate profile is applied to the IGBT. The collector voltage and current transients are shown in

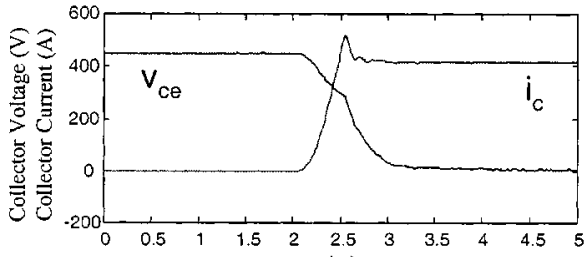

(a)

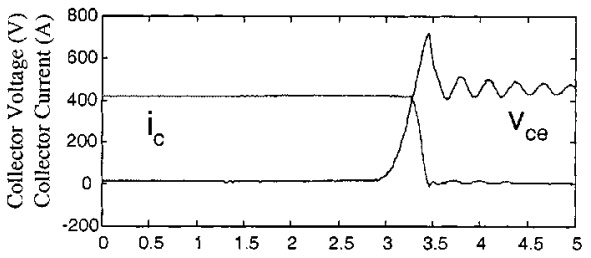

(b)

Time ( $(\mu s)$

Fig. 12. Detail of switching transients. (a) Turn-on. (b) Turn-off.

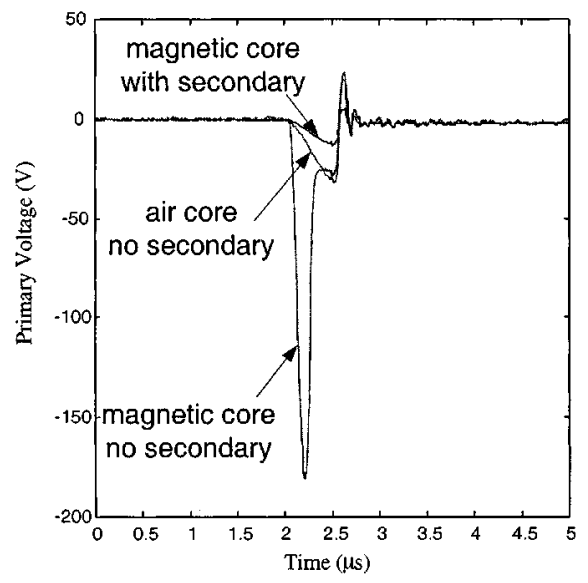

Fig. 13. Coaxial transformer primary voltage at turn-on.

Fig. 11. The duration of the first pulse is controlled to build up the desired current level in the load inductor. The turn-off characteristics can be studied under this condition. The second pulse is used to study the turn-on commutation. The double-pulse sequence is triggered at a very low repetition rate to assure zero initial conditions.

For evaluation of the CCT, the specific turn-on and turn-off transients are indicated in Fig. 11 and expanded in Fig. 12. At these instants, voltage drop across the transformer primary circuit is measured and the transformer primary impedance is calculated. Three different tests are performed. In the first test, the complete CCT is used and the secondary current is measured. This test condition is defined by the load and kept unchanged in all tests. In the second test, the core and secondary winding are eliminated and the primary circuit is tested alone. Finally, only the core is reinserted and the primary circuit is tested without the shielding effect of the shorted secondary circuit.

Since the load impedance mainly determines the current behavior for the first and second test, the transformer insertion inductance can be evaluated using the known current variation and measuring the transformer primary voltage. Fig. 13 shows the CCT primary voltage transients at turn on for the three different cases. Without the shielding effect of the secondary winding, the insertion inductance increases causing a higher primary voltage. 


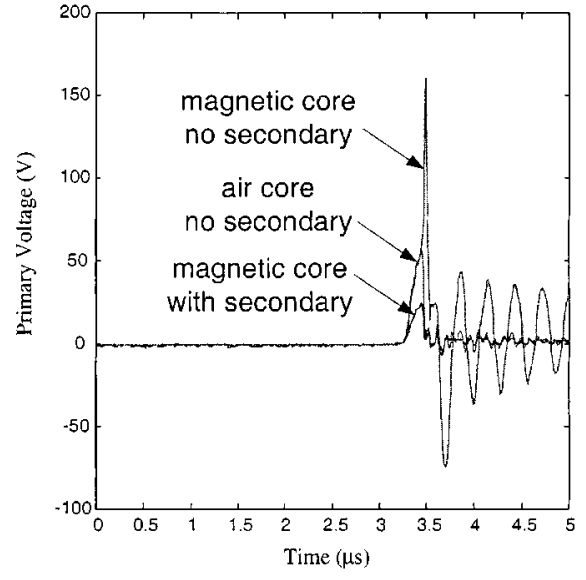

Fig. 14. Coaxial transformer primary voltage at turn-off.

TABLE I

PRIMARY IMPEDANCE (AT 10 MHz FOR FEA AND THEORETICAL)

\begin{tabular}{llll}
\hline Case & Calculation & Resistance $(\mathrm{m} \Omega)$ & Inductance $(\mathrm{nH})$ \\
\hline Air Core; No Secondary & Theoretical & 1.0 & 7.3 \\
& Finite Element & 0.79 & 7.2 \\
& Experimental & 4.8 & 13.5 \\
\hline Magnetic Core; No Secondary & Theoretical & 1.0 & $285 \times 10^{3}$ \\
& Finite Element & 5.2 & $144.3 \times 10^{3}$ \\
& Experimental & 4.8 & \\
\hline Magnetic Core; With Secondary & Theoretical & 1.0 & 1.56 \\
& Finite Element & 1.58 & 1.8 \\
& Experimental & 4.8 & 5.7 \\
\hline
\end{tabular}

In the third case the core saturates causing the inductance and therefore the voltage to decrease. The inductance reduces to only that of the primary circuit loop if the magnetic core is eliminated. This causes reduction of the primary voltage for the same current transient. For the complete CCT, the insertion inductance is even lower due the shielding effect of the secondary loop and the lowest voltage peak at turn-on is obtained. The same behavior is obtained at turn-off as shown in Fig. 14. The primary circuit resistance is evaluated using voltage drop and current flow under on state after the switching transient conditions. Using the turn-on and turn-off transients, the CCT insertion impedance is calculated, and the results for each case are summarized in Table I.

The experimental measurement of the resistance is higher because it includes the contact resistance of the bus connections. The theoretical calculation for resistance does not take into account the change in the current path due to the presence of the core or the secondary winding. Both theoretical and FEA are s performed at $10 \mathrm{MHz}$. The frequency content during the experimental measurement is different. The experimental data for inductance with the magnetic core and no secondary winding causes the current profile in the switch to change. Hence, the value of the inductance cannot be accurately measured without additional current measurement in series with the power switch. The capability to measure high-frequency content due to the large di/dt $(2.2 \mathrm{kA} / \mu \mathrm{s})$ is evident from Fig. 12. The measured rise times in the set up are of the order of $10 \mathrm{~ns}$. Using $f_{e}=$

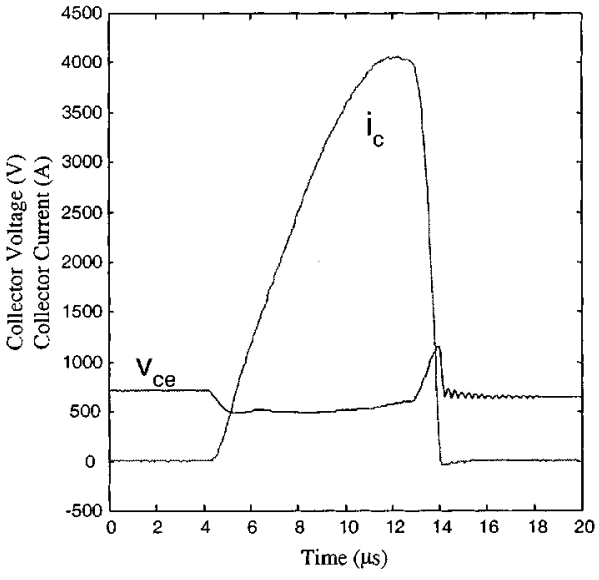

Fig. 15. Measurement using the CCT for IGBT short-circuit test.

$1 /\left(\pi T_{\text {rise }}\right)$, one can calculate an effective upper frequency of $30 \mathrm{MHz}$ for the CCT measurements.

2) Short-Circuit Test: A basic concern in any electromagnetic measurement device is avoiding saturation of the magnetic path. Saturation causes errors in the measured data. The CCT structure results in very low flux values inside the core. Thus, no magnetic saturation is expected for a wide range of input currents.

To evaluate the transformer's ability in measuring higher currents, a short-circuit test is performed in which currents as high as $4000 \mathrm{~A}$ are allowed to flow for a short period of time. The IGBT collector voltage and current are plotted in Fig. 15. One can observe that, even for high currents, the core does not saturate, preserving the measurement accuracy.

3) Air Core Transformer: The importance of the magnetic core in coupling the primary and secondary circuits is outlined when current is measured using an air core transformer. In this topology, the same geometry of primary and secondary windings is used, but the magnetic core is replaced by an air core. Fig. 11 shows the collector voltage transient and the measured collector current for the magnetic and air core transformers. At the high $d i / d t$ transients, the secondary current follows the primary current. However, after the transient, secondary current decays exponentially. This means that the air core transformer is only capable to measure extremely high $d i / d t$ transients.

\section{B. MTO Characterization}

The test setup in Fig. 1 is used on the characterization of MTO devices. Fig. 16(a) and (b) shows measurement of the MTO current for turn-on and turn-off transients of switch $S_{1}$, respectively. The high switching rates demonstrate the high bandwidth of the test setup. In Fig. 16(a), $d i / d t$ is $188 \mathrm{~A} / \mu \mathrm{s}$ and it is significantly higher at turn-off, before the tail current interval. An interesting characteristic also captured by the proposed current measurement scheme is the anode current peaking at turn-off, caused by voltage transients in the gate-cathode junction. Anode current peaking has been detected in similar arrangements employing regular gate-turn-off (GTO) thyristors.

Better utilization of the power devices is one of the main features of the resonant snubber structure. The placement of the snubber capacitor right across the device minimizes the stray 


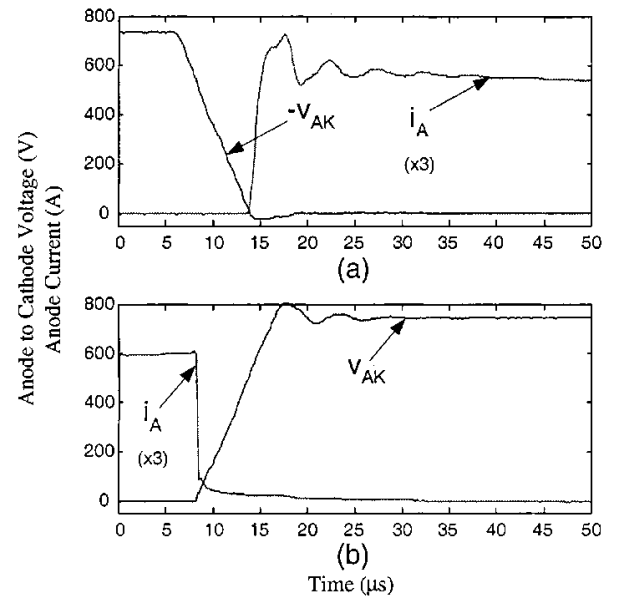

Fig. 16. MTO switching waveforms measured using the CCT at a load current level of 200 A. (a) Turn-on. (b) Turn-off.

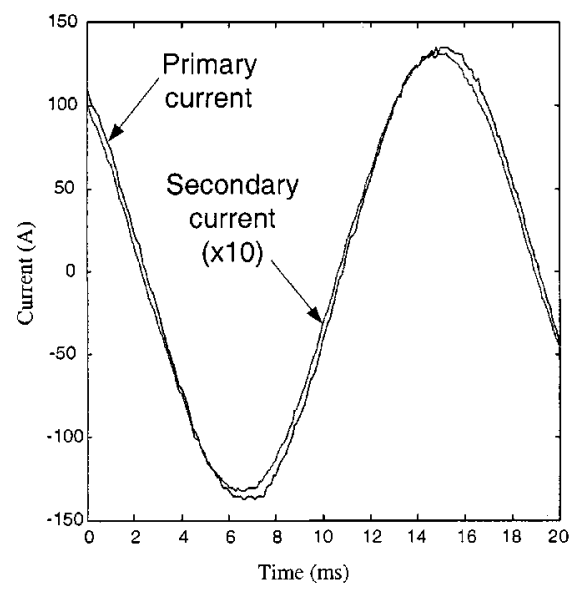

Fig. 17. Low-frequency current measurement using the CCT. The primary current is $95-\mathrm{A} \mathrm{rms}$ at $60 \mathrm{~Hz}$. The secondary current is 9.2-A rms and the phase error is $4.3^{\circ}$.

inductance in this loop and the associated peak power dissipation at turn-off. Notice the negligible voltage spike in Fig. 16(b). This characteristic confirms the low insertion impedance of the $\mathrm{CCT}$ and its adequacy for measurements in very low inductance circuits, such as the capture of transient device current in topologies employing a resonant snubber.

\section{Low-Frequency Characterization}

From the response of the CCT shown in Fig. 10, it has gain of 0.83 at $2 \mathrm{~Hz}$. The CCT shows onset of saturation at $0.5 \mathrm{~Hz}$ and primary current of $0.5-\mathrm{A} \mathrm{rms}$. The CCT was tested at $60-\mathrm{Hz}$ frequency to obtain its gain using a large signal at low-frequency excitation. Fig. 17 shows that the CCT can carry currents up to 95-A rms at $60 \mathrm{~Hz}$. The current gain is close to the ideal value and phase error is $4.3^{\circ}$ at $60 \mathrm{~Hz}$.

\section{CONCLUSION}

An accurate current measurement technique for characterization of high-power semiconductor devices has been proposed and studied in detail. The basic component is a coaxial current transformer, characterized by its low insertion resistance and inductance. Analytical and computational models (2-D and 3-D) have been developed and used in the determination of the CCT parameters and bandwidth. Experimental results confirm the predicted wide bandwidth and low insertion impedance of the proposed measurement system. Results for different types of applications, such as laminated bus for power modules and clamps bus structure for press-pack setups, were presented along with FEA of the CCT. These results show that this easily constructed CCT can yield accurate results with a bandwidth from $2 \mathrm{~Hz}$ to $30 \mathrm{MHz}$ with very low insertion impedance.

\section{REFERENCES}

[1] D. Braun, R. Lukaszewski, D. Pixler, and G. Skibinski, "Use of co-axial CT and planar bus to improve IGBT device characterization," in Conf. Rec. IEEE-IAS Annu. Meeting, San Diego, CA, Oct. 1996, pp. $1507-1516$

[2] N. Karrer and P. Hofer-Noser, "A new current measuring principle for power electronic applications," in Proc. IEEE Int. Symp. Power Semiconductor Devices and IC's, 1999, pp. 279-282.

[3] W. F. Ray and R. M. Davis, "Wide bandwidth Rogowski current transducers," EPE J., vol. 3, no. 1, pp. 51-59, Mar. 1993.

[4] M. H. Kheruluwala, D. W. Novotny, and D. M. Divan, "Co-axially wound transformers for high-power high-frequency applications," IEEE Trans. Power Electron., vol. 7, pp. 54-62, Jan. 1992.

[5] B. Cardoso Filho and T. A. Lipo, "Application of MTO thyristors in current stiff converters with resonant snubbers," in Conf. Rec. IEEE-IAS Annu. Meeting, Phoenix, AZ, 1999, pp. 1871-1878.

[6] V. John, B. S. Suh, and T. A. Lipo, "An active gate drive with three-stage control and fast protection for high power IGBTs," presented at the EPE Conf., 1999, Paper 102.

[7] G. Kibinski, "Design and implementation of a passive clamp RDCLc onverter," Ph.D. dissertation, Dep. Elect. Comput. Eng., Univ. Wisconsin,, Madison, WI, 1992.

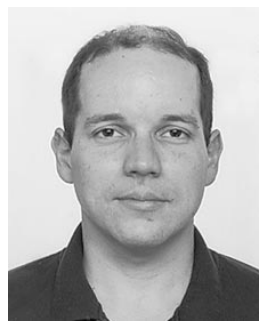

Renato O. C. Lyra (S'98) was born in Belo Horizonte, Brazil. He received the B.E.E. and M.E.E degrees in electrical engineering from the Universidade Federal de Minas Gerais, Belo Horizonte, Brazil, in 1991 and 1994, respectively. He is currently working toward the Ph.D. degree at the University of Wisconsin, Madison.

Since 1994, he has been with the Department of Electrical Engineering, Universidade Federal de Minas Gerais, as an Assistant Professor. His primary areas of interest are electrical machines design, motor drives, and renewable energy systems.

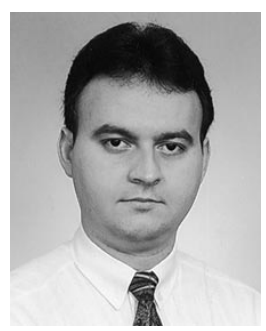

Braz J. Cardoso Filho (S'95-M'98) was born in Fortaleza, Brazil. He received the Electrical Engineering (with the EEUFMG Lucio do Santos Award) and Master of Electrical Engineering degrees from the Universidade Federal de Minas Gerais, Belo Horizonte, Brazil, and the $\mathrm{Ph}$. D. degree from the University of Wisconsin, Madison, in 1987, 1991, and 1998, respectively.

In 1988, he joined the Department of Electrical Engineering, Universidade Federal de Minas Gerais, where, in 1991, he became an Assistant Professor. He has developed teaching and research activities in the power electronics area. His areas of interest include multimegawatt converters, power devices, and electric drive systems. 


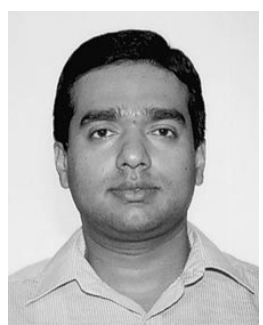

Vinod John (S'92-M'00) received the B.Tech. degree in electrical engineering from the Indian Institute of Technology, Madras, India, the M.S.E.E. degree from the University of Minnesota, Minneapolis, and the Ph.D. degree from the University of Wisconsin, Madison, in 1992, 1994, and 1999, respectively.

He is currently an Electrical Engineer in the Electrical Systems and Technologies Laboratory, Corporate Research and Development, General Electric Company, Schenectady, NY. His primary areas of interest are power semiconductor device technology, high-power hardand soft-switched converters and their control, and motor drives.

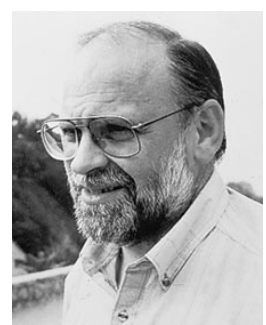

Thomas A. Lipo (M'64-SM'71-F'87) is a native of Milwaukee, WI. He received the B.E.E. and M.S.E.E. degrees from Marquette University, Milwaukee, WI, in 1962 and 1964, respectively, and the Ph.D. degree in electrical engineering from the University of Wisconsin, Madison, in 1968.

From 1969 to 1979, he was an Electrical Engineer in the Power Electronics Laboratory of Corporate Research and Development, General Electric Company, Schenectady, NY. He became Professor of Electrical Engineering at Purdue University, West Lafayette, IN, in 1979 and, in 1981, he joined the University of Wisconsin, Madison, in the same capacity. He is presently the W.W. Grainger Professor for Power Electronics and Electrical Machines, Co-Director of the Wisconsin Electric Machines and Power Electronics Consortium, and Director of the Wisconsin Power Electronics Research Center.

Dr. Lipo has received the Outstanding Achievement Award from the IEEE Industry Applications Society, the William E. Newell Field Award from the IEEE Power Electronics Society, and the 1995 Nicola Tesla IEEE Field Award from the IEEE Power Engineering Society for his work. Over the past 30 years, he has served the IEEE in numerous capacities, including President of the IEEE Industry Applications Society. 